\title{
DEVELOPMENT OF A \\ GENERIC KNOWLEDGE STRATEGY TYPOLOGY
}

\author{
Paul E. Bierly III \\ James Madison University \\ Harrisonburg, VA
}

\begin{abstract}
Knowledge strategies are the set of strategic choices related to firms'knowledgebases that provide a guideline for strategic action. In this paper, we develop a variety of possible generic knowledge strategies and discuss how they can be internally consistent, mutually reinforcing, and lead to a sustainable competitive advantage.
\end{abstract}

\section{Introduction}

Over the last several years a knowledge-based view of the firm has blossomed and has provided a fresh, new perspective for the study and development of organizational design and strategic management (Grant, 1996a, b; Spender, 1996; Nonaka, 1994; Conner \& Prahalad, 1996). According to this view, the principal function of an organization is the creation, integration, and application of knowledge. Sustainable competitive advantages and performance differences are the result of firms having unique knowledge-bases and their capability of managing their different knowledge areas. Several authors have relied on the principles of the knowledge-based view to propose improvement in organizational design. For example, Hedlund (1994) developed an N-form organizational structure to facilitate knowledge integration and Sanchez and Mahoney (1996) illustrated the importance of modularity with respect to product and organizational design to facilitate knowledge management. In addition, a number of scholars have illustrated the importance of a knowledge-based view to successfully manage strategic alliances (Hamel, Doz \& Prahalad, 1989; Hamel, 1991; Mowery, Oxley \& Silverman, 1996).

A knowledge-based view of the firm has also reshaped the field of strategic management. ${ }^{1}$ Some, such as Spender (1996), go so far as to suggest the field is in the middle of a paradigm shift. Today, when managers develop a strategy outlining how they will compete in their different industries, they are strongly advised to focus on their core competencies and capabilities (Hamel \& Prahalad, 1994; Prahalad \& Hamel, 1990; Leonard-Barton, 1995). The essence of strategy, the development of sustainable competitive advantages, can then be viewed as the development and application of these core competencies. However, to date this advice to become a learning (i.e., Senge, 1990; Garvin, 1993) or knowledgecreating company (i.e., Nonaka, 1991; Leonard-Barton, 1995) has mostly guided organizations to try to maximize their learning and has not addressed the specific 
strategic choices that arise in this process. These sets of strategic choices are what we refer to as the firms' generic knowledge strategies and provide firms with a guideline for strategic action.

Other generic strategy typologies, such as Porter's (1980) (low cost, differentiation, and focus), have emphasized that, for each type of generic strategy, there must be consistency of strategic actions, organizational design, control systems, human resource systems, and organizational culture. Thus, each of the different generic strategies provide a fundamentally different approach to the strategic management of the firm. Each of the different generic strategies seek to create and sustain competitive advantages using different internally consistent sets of resources, skills and systems.

The purpose of this paper is to develop a variety of possible generic knowledge strategies and discuss when and how they can be internally consistent, mutually reinforcing, and lead to a sustainable competitive advantage. Thus, the underlying basis of our generic knowledge strategies, the need for internal consistency in strategic decisions, is similar to the rationale for the development of other generic strategies such as Porter's, except that ours is narrower in focus and based on a knowledge-based perspective. Elsewhere, exploratory empirical studies have identified the existence of different approaches to knowledge management in specific settings (Henderson \& Cockburn, 1994; Pisano, 1994; Bierly \& Chakrabarti, 1996a). Our aim is to develop a broad-based typology of generic knowledge strategies and also explain why certain combinations of strategic knowledge decisions are unlikely to be successful in certain conditions.

\section{The Nature of Organizational Knowledge}

Knowledge is a highly contentious, abstract, and multifaceted concept that has challenged the greatest minds of the world. It is related, but clearly different, than concepts such as information, technology, science and truth. Webster's (1981: 1252) defines knowledge as the "acquaintance with or theoretical or practical understanding of some branch of science, art, learning, or other area involving study, research, or practice and the acquisition of skills." Key elements of the concept of knowledge are: (a) that knowledge can be created through experience (empiricism) or reason (theory), (b) the development or acquisition of some skills is critical to the enhancement of knowledge, (c) knowledge is a "broad" concept in the sense that it includes but is not limited to science, art, information and technology, and a "deep" concept in that it requires understanding of the area, and (d) there are different types of knowledge. Knowledge and learning can be viewed as inextricably related concepts in the following manner: knowledge is a stock variable and learning is a flow variable. At a given point of time, an individual or group possesses a stock of knowledge and this stock is changed over time by a learning process (or unlearning in the case where the stock is depleted). 
Concerning organizational knowledge, most of the research has focused on describing and categorizing different types of knowledge and explaining the differences between individual and social knowledge (Spender, 1994). An important distinction of knowledge is between tacit and explicit knowledge. Knowledge can be classified as explicit if it can be transferred from one individual to another using some type of formal communication system. Thus, explicit knowledge must be articulable or codifiable. On the other hand, tacit knowledge is generally viewed as knowledge that cannot be formally communicated (Polanyi, 1966). Tacit knowledge is deeply rooted in one's experience and own "mental model." The distinction between explicit and tacit knowledge is important when we evaluate competitive differences between firms. Tacit knowledge is more valuable and more likely to lead to a sustainable competitive advantage than explicit knowledge because it is much harder for competitors to imitate (Winter, 1987; Kogut \& Zander, 1992; Zander \& Kogut, 1995). Inimitability is further increased when the knowledge is complex and combined with other types of knowledge in an unclear fashion; that is, there is causal ambiguity (Kogut \& Zander, 1992; Lippman \& Rumelt, 1982).

Even though the importance of tacit knowledge is stressed in many theoretical discussions, the usefulness of the concept is limited due to the vagueness and complexity of the topic. Specifically, the concept of tacit knowledge is vague because there is not an accurate and precise definition of what it is; instead the focus is on what it is not. It is knowledge that is not codifiable or explicit. Due to the vagueness of the term, it is essentially impossible to conduct useful empirical research to determine the different impact of tacit and explicit knowledge. In addition, almost no knowledge is fully tacit or explicit; most "complex" knowledge is difficult to transfer and often meaning is altered during the transfer. Knowledge that may be easy to transfer between two specific individuals may be very difficult to transfer between two other individuals due to different training, language, and mental models. Thus, instead of classifying knowledge as either tacit or explicit, it is probably more appropriate to discuss different degrees of tacitness for different situations.

When discussing the concept of organizational knowledge it is also important to clarify the difference between individual, group and organizational learning. According to Simon (1991), all knowledge is initially created or acquired by individuals. Individual learning is a prerequisite for organizational learning. After an individual learns, knowledge is first passed on to other "close" individuals who share similar interpretation frameworks, or what Brown and Duguid (1991) refer to as a community-of-practice. This social context of knowledge transfer between individuals is an extremely important part of the process of organizational learning (March, 1991). Besides having the ability to create or interpret new ideas from outside sources, "expert" individuals must also have the social skills to pass the knowledge to others. More explicit knowledge may be easily passed from one individual to another, but more tacit knowledge may require informal and difficult methods, such as the use of 
stories or metaphors (Brown \& Duguid, 1991). However, the collective knowledge of the group often is much more than the sum of the individuals' knowledge. Synergies exist between individuals as the knowledge is integrated and reinterpreted by others (Spender, 1994). Group norms can be used to store certain types of knowledge and pass them on to others.

Organizational knowledge can be viewed as the integration of group knowledge, mainly through middle level managers (Nonaka, 1994). Generally speaking, organizational knowledge is referred to that knowledge that has diffused throughout the entire organization. However, in reality this is rarely the case since not all individuals have the ability to interpret and understand the new knowledge. Whereas it may be difficult to transfer knowledge to other work groups and there may be limited incentive to do so, it usually is critical to transfer knowledge up through an organization to the key strategic decision makers who allocate resources. Once knowledge has reached the top of the organization, it then becomes institutionalized and forms the basis for new organizational rules, procedures and routines, which are the means that the knowledge is stored within the organization. Then other individuals are socialized to the new organizational beliefs (March, 1991). This process of mutual individual and collective learning is never-ending. In addition, as the knowledge is transferred up and down the organization, the knowledge spirals and expands through different conversion modes, including the conversion of tacit knowledge to explicit knowledge, and vice-versa (Nonaka, 1994). Over time, the knowledge becomes embedded in routines (Nelson \& Winter, 1982), and after employees come and go throughout the organization the organization's knowledge-base becomes distinct from the aggregate knowledge of individuals at a specific point of time.

The processes of knowledge transfer within an organization and across organizations creates a dilemma for the strategic decision makers of an organization (Kogut \& Zander, 1992). The transfer of knowledge within the firm is maximized if the knowledge is more codifiable and simple. Members of the organization outside the community-of-practice can readily interpret, understand, and integrate the knowledge with their own knowledge-base. However, the more codifiable and simple the knowledge becomes, the easier it is for competitors to imitate. Thus, actions by a firm to maximize the speed and quantity of knowledge transferred within the organization typically are inconsistent with actions to limit the flow of the knowledge outside the organization.

\section{The Evolution of the Knowledge-Based View of the Firm}

The current focus on the importance of knowledge, and the strategic implications of a firm's knowledge structure, has evolved from three different, but related, streams of research. First, organizational theorists have attempted to develop a general theory of organizational learning. Even though there is widespread acceptance of the notion of organizational learning and its importance to 
organizational performance, no model of organizational learning is widely accepted (Fiol \& Lyles, 1985). Huber (1991) argues that the effort to develop a general theory of organizational learning has been mostly unsuccessful for the following reasons.

(a) Each theorist, or group of theorists, defines organizational learning quite differently. For example, Fiol and Lyles define organizational learning as "the process of improving actions through better knowledge and understanding" (1985, p. 803). This narrow definition requires a change in behavior of the organization to ensure learning has occurred. Alternatively, according to Huber "an entity learns if, through its processing of information, the range of its potential behaviors is changed" (1991: 89). This broader definition specifically does not require a change in behavior; he argues organizations can "learn" and decide not to act on their new knowledge. Weick (1991) argues that in some cases, there is too much reliance on the traditional (stimulus-response) definition of learning, which most psychologists and experts in learning view as a very limiting case of learning and do not support as a general framework.

(b) Many researchers only attempt to analyze a specific type of organizational learning or a specific part of the learning process. For example, whereas some researchers focus on adaptive learning (e.g., Hedberg, Nystrom \& Starbuck, 1976; Nystrom \& Starbuck, 1984), others focus on vicarious learning (e.g., Gilad \& Gilad, 1988), and still others focus on experiential learning (e.g., Argyris, 1982; Argyris \& Schon, 1978). Furthermore, whereas each of the above researchers is primarily focusing on information acquisition, others have focused on information distribution (e.g., Huber, 1982; Huber \& Daft, 1987), information interpretation (e.g., Daft \& Weick, 1984), or organizational memory (e.g., Nelson \& Winter's, 1984, discussion of routines and Gioia \& Poole's, 1984, discussion of scripts).

(c) There is little integration of these different views (Huber, 1991; Fiol \& Lyles, 1985) and support for the theoretical arguments is limited and is usually based on computer simulation models (e.g. Cyert \& March, 1963; Levinthal \& March, 1981; March, 1991; Lant \& Mezias, 1992) or case studies (e.g. Brown \& Duguid, 1991; Bierly \& Spender, 1995). Recent attempts to synthesize this literature and standardize terminology, such as Miller (1996), have not yet been generally accepted.

Second, a group of strategic management theorists have focused on the importance of organizational capabilities (Prahalad \& Hamel, 1990; Teece, Pisano \& Shuen, 1997; Leonard-Barton, 1992, 1995; Stalk, Evans \& Shulman, 1992). They view the central issue of strategy as the development of a set of core capabilities or competencies that will provide a competitive advantage. Most of these theorists believe that the firm's knowledge structure and its ability to leam are the backbone of this approach to strategy and some have viewed learning as the meta-capability that is the principal driver of all other organizational capabilities (e.g., Lei, Hitt \& Bettis, 1996). Prahalad and Hamel define core competencies, which they claim are the roots to competitive advantage, as "the collective learning in the organization, especially how to coordi- 
nate diverse production skills and integrate multiple streams of technologies" (1990: 82). This "school" of strategy, which evolved from the resource-based view of the firm, has become very popular and has recently influenced the strategic thinking of many corporate executives.

Third, organizational theorists that study innovation and the management of technology have increasingly focused on the firm's knowledge structure and its reconfiguration (Henderson \& Clark, 1990; Cohen \& Levinthal, 1990; Imai, Nonaka \& Takeuchi, 1988; Wheelwright \& Clark, 1992). The study of conditions for successful innovation (e.g., Kanter, 1988) are inextricably related to the conditions required for organizational learning. Technology can be viewed as one type of organizational knowledge and the study of technology transfer can be considered a specific type of knowledge acquisition and distribution. Most of these researchers focus on the development of new products and processes, and specifically the explicit technologies associated with these innovations. Only recently have researchers in this field shifted their attention to the tacit knowledge associated with innovations and realized how different knowledge environments affect the innovation process (e.g., Cohen \& Levinthal, 1990; Pisano, 1994). In a similar manner, earlier research on technology strategies (e.g., Maidique \& Patch, 1983) has some similarities to what we are terming knowledge strategies.

Broadly speaking, the major thrust of each of these three streams of research is that the management of a firm's knowledge-base and its ability to learn are critical to its success. But each group is looking at the process of learning and its purpose from different perspectives. Most of the researchers in the organizational learning group are addressing issues related to the adaptive behavior of firms in response to a change in the environment. Many of them place narrow boundaries on the concept of learning in the sense that they only consider learning to occur if actions have visibly changed (i.e., Argyris \& Schon, 1978; Fiol \& Lyles, 1985; see Huber, 1991, for a detailed discussion of the shortcomings of this narrow view). Alternatively, the strategic management group outlined above takes the perspective that learning is a more creative and proactive process. Their focus is on the development of new, inimitable capabilities that lead to a sustainable competitive advantage. The management of technology perspective of learning is different than the other two views in that most of the work in this area is narrowly focused on the new product development process. The knowledge-based view of the firm essentially can be viewed as a holistic approach that includes and integrates these three different streams of research.

\section{Elements of a Knowledge Strategy}

To date, the research discussed above has expanded our understanding of the descriptive process of knowledge generation and application within a firm. However, recommendations of how to best become a learning or knowledge-creating organization have been very broad and not too practical. The advice of most "ex- 
perts" (e.g. Senge, 1990; Nonaka, 1991) is that managers need to develop the proper climate to foster learning and creativity. Essentially, managers are simply guided to maximize learning as best they can.

However, we believe that there are several critical strategic choices managers make, either as part of an explicit or implicit strategy-making process, that provide the foundation for their knowledge strategy. These decisions may or may not be explicitly declared by top management. Often they are implied by top management's actions regarding the allocation of resources and the establishment of different customs, goals, procedures and incentive systems. Nevertheless, these decisions shape and direct the organization's learning process and, subsequently, determine the firm's knowledge-base. Our intention is not to imply that there is one best strategy that will maximize learning, but quite the contrary, we propose that there are several internally consistent generic knowledge strategies that may be successful in certain circumstances.

We propose that there are four basic tradeoffs that require strategic decisions concerning knowledge management.

(1) Internally vs. externally sourced knowledge.

(2) Enhanced vs. new knowledge.

(3) Fast vs. slow speed of learning.

(4) Depth vs. breadth of knowledge-base.

For each of these four areas, there are advantages and disadvantages of placing stronger emphasis in one or the other direction. Ideally, organizations would prefer to achieve the best of both worlds concerning these tradeoffs, however this usually can not be accomplished due to limited resources, cultural conflict, and a need for internal consistency. We define a firm's generic knowledge strategy as the collective responses to these four strategic choices, whether each of the responses is a formally stated decision or a more emergent, culturally-driven reaction to a perceived environmental condition.

\section{Internally vs. Externally Sourced Learning}

Internal learning is the generation and distribution of new knowledge within the boundaries of the firm. External learning can be defined as a two step process where, first, boundary spanners are exposed to knowledge from an outside source and, second, the knowledge is passed on throughout the organization. Ideally, firms want to excel at both internal and external learning, but this is rarely the case. Due to limited resources, limited management attention, and the nature of the firm's culture, firms tend to focus more and excel at either internal or external learning. For example, firms that develop a strong sense of pride in being the leaders in knowledge development in a certain field may be skeptical and resistant to the ideas of outsiders. On the other hand, firms that are excellent at benchmarking may become experts at improving products and processes within a given frame of reference, but may lack the creativity and out-of-the-box thinking required to generate new ideas internally. 
From one point of view, internal learning is most critical to the development of core competencies, competitive advantages and superior profits (Bierly \& Hämäläinen, 1995). If a competency is to be unique to a firm and inimitable to competitors, it must be internally developed and not obtained from an outside source that is also available to others. Additionally, certain types of knowledge need to be internally sourced. Specifically, systemic knowledge, which is defined as knowledge that is complexly integrated with other knowledge areas, should be internally sourced so that the firm can better understand and have more control over the development process (Chesbrough \& Teece, 1996). The tacit nature of systemic knowledge essentially makes it nearly impossible to obtain from an outside source.

From another point of view, a strong focus on external learning has several advantages to a firm. A firm can develop a broader knowledge-base and keep in touch with leading technologies by maintaining an external focus. This broader knowledge-base allows a firm to have more strategic flexibility and be more adaptive to changing environments (Bierly \& Chakrabarti, 1996c; Grant, 1996b). Costs can be reduced since there is less "reinventing the wheel." However, excessive reliance on external learning may degrade a firm's internal learning skills to such an extent that it may be difficult to maintain core competencies and sustainable competitive advantages. For example, Hitt, Hoskisson, Ireland and Harrison (1991) illustrated that increased reliance on acquisitions as a source of new products often results in reductions in both R\&D inputs and outputs. This study supports, in a limited case, our assertion that there exists tradeoffs between internal and external learning and it is very difficult for a firm to excel at both.

This dimension of internal vs. external learning is further complicated in the sense that the two are mutually interdependent and complimentary processes. To be successful at external learning, members of the firm must already have enough knowledge in the area to understand, interpret and realize the benefits of the external knowledge source. This ability to internalize outside knowledge, which Cohen and Levinthal (1990) refer to as "absorptive capacity," can be enhanced by internal learning methods, such as internal $R \& D$, production experience, and technical training. Likewise, external learning can facilitate the internal learning process by providing a source of new ideas and a different perspective for viewing both problems and opportunities. No company is so large that they have enough resources to excel at all areas and can not benefit from advice from others. In summary, it is hard to imagine a successful firm that is poor at either internal or external learning. Both are important to the success of the firm, but usually a firm can not aggressively pursue both simultaneously due to limited resources and various tradeoffs. Firms determine the balance of internal and external learning that is best for them based, in part, on the other dimensions of their knowledge strategy.

\section{Enhanced vs. New Knowledge}

Another dimension of a firm's knowledge strategy is whether the firm focuses more on new, original knowledge or on enhancing knowledge domains they 
already understand. Product innovations based on new knowledge are usually classified as radical, whereas innovations based on enhanced knowledge are incremental (see Tushman \& Anderson, 1986). Concerning the learning process, firms that focus on enhancing the current knowledge-base usually stay within a given frame of reference, which Argyris and Schon (1978) refer to as single-loop learning. Firms that focus on new knowledge areas typically must challenge basic assumptions, values and mental models, which is referred to as double-loop learning. Similarly, March (1991) outlined the tradeoffs associated with the exploitation of current knowledge that maximizes profits in the short-run, and the exploration of new knowledge that maximizes long-term success. Exploration is costly and risky, but is more likely to lead to a sustainable competitive advantage. Too much focus on exploration does not allow firms to reap the benefits from its breakthroughs. On the other hand, March (1991) has illustrated how firms that focus too much on exploitation typically find themselves trapped in suboptimal stable equilibria. They may become experts in an area that has become obsolete. However, few firms are successful at developing both enhanced and new knowledge, primarily because there are usually limited resources within the firm (Levinthal \& March, 1993). However, other researchers (e.g., Volberda, 1996; Hedlund, 1994) have also pointed out that focusing on new knowledge and focusing on enhancing a current knowledge-base often require different types of organizational cultures and structures.

\section{Learning Speed}

In essence, this decision concerning speed of learning comes down to the practical decisions about how much resources should be allocated to further speeding up the learning process. In general, firms want to learn and develop new products as fast as possible. In many industries, such as the computer and computer software industries, time is an important source of competitive advantage (Stalk, 1988; Bower \& Hout, 1988). In such industries, first-mover advantages typically outweigh additional development costs and risk associated with being aggressive (see Lieberman \& Montgomery, 1988). However, learning too fast and committing oneself to a specific knowledge trajectory may create major problems if one ends up on the "wrong branch of the tree" (Levinthal \& March, 1981). When environmental signals are ambiguous and make learning difficult, it is often better to learn at a slower rate to ensure reliability (Herriott, Levinthal \& March, 1985; Lounamaa \& March, 1987). Once a firm proceeds along a certain knowledge trajectory, it may be difficult to switch to a different trajectory because (a) the firm may be too far behind competitors in the other area and (b) it may be difficult to garner internal support to change, especially if the current learning path has experienced at least moderate success (March, 1991). Additionally, slower learning may allow complementary knowledge streams to progress together, allowing for the better integration of different knowledge areas and, in the end, a superior collective knowledge-base. 
This dimension of learning speed can also be influenced by the internal vs. external learning dimension outlined above. There is a debate whether more internal or external learning increases innovation speed. Some research has indicated that more internal learning will decrease technology cycle time and increase learning speed (Bierly \& Chakrabarti, 1996b). If a firm generates new knowledge internally, such as in its $R \& D$ lab, it will have a much deeper understanding of the knowledge than outsiders and will probably face fewer internal organizational barriers to change. Most likely, there will be a strong commitment toward the technology by the employees and a sense of ownership. Also, it is much more likely to have a strong champion within the organization that will be able to overcome others' natural resistance to change and obtain necessary resources for further development (Chakrabarti, 1974). External learning is often slower because a) there is no internal champion, b) it may be difficult to interpret and understand the external knowledge, and c) the "not invented here" syndrome may be a substantial barrier.

Other researchers have argued the opposite: more reliance on external learning will increase learning speed (Kessler \& Chakrabarti, 1996; Gold, 1987; Meyer, 1993). This counter argument stresses the importance of not "reinventing the wheel" and using partners to keep abreast of cutting-edge technologies. Since no firm can efficiently develop a broad range of technologies, they should focus on the few that they can best develop and rely on others to provide supporting technologies. To summarize, there probably is not a simple linear relationship between technology sourcing and learning speed. Both internal and external learning can support and hinder the speed of learning in different ways, depending on the situation.

\section{Breadth of Knowledge-base}

The final dimension of a firm's knowledge strategy is the decision of whether the firm should develop a narrow and hopefully deep knowledge-base or a broad and shallow knowledge-base. Again, with limited resources firms cannot realistically pursue both a broad and deep base. According to Hamel and Prahalad (1994), most firms are better off if they focus on specific domains of knowledge (core competencies) so that they can become leaders in those areas. They illustrated the strategic importance of developing core products and a depth in a few critical knowledge areas in a wide range of cases. However, for some firms the opposite strategy may be more successful. If firms have a broader knowledge-base they are better able to combine related technologies in a more complex manner, which can create causal ambiguity and sustainable competitive advantages (Reed \& DeFillipi, 1990). Additionally, if a firm's knowledge-base is too narrow, its core capabilities may evolve into core rigidities since the firm may lack the ability to monitor and adapt to advances in different but related knowledge areas (LeonardBarton, 1992). In general, a broader knowledge-base results in increased strategic flexibility and allows firms to be more adaptive to external changes (Grant, 1996a; Volberda, 1996). 


\section{One Best Knowledge Strategy in an Industry?}

Spender (1989) illustrated that within an industry an 'industry recipe' develops that can be viewed as a shared set of ideas that become institutionalized and provide a guide to action. He defined strategy as "the intellectual response to the uncertainties present in the managers' ideas and data about the organization" (Spender, 1989: 186). However one could, incorrectly, extend this framework to assume that since firms within an industry share a common industry recipe, then they would have common beliefs concerning uncertainty resolution and learning; similar rational intellectual responses would result in all firms following the one best knowledge strategy in the long run. This line of reasoning is faulty for several reasons. First, industry recipes are changing rapidly in many industries due to radical technological advances and the blurring of industry boundaries. Firms adapt to these changes of industry recipes at different rates, thus creating groups of firms with each group following a different recipe at a given point of time. Second, even if a dominant industry recipe exists, firms may choose different knowledge strategies because they have different histories, organizational cultures, resources and capabilities, and because they are at different evolutionary stages. Even though in the long run these differences may tend to converge if the industry recipe remains constant and the environment remains stable ${ }^{2}$, this would not be the case if the industry recipe continually changes, especially if the recipe changes at a faster rate than the organizations can change their cultures, capabilities, etc. Third, determining industry boundaries is a difficult and somewhat arbitrary process. A different industry recipe may evolve for the different segments of an industry, each with different competitive environments, which could result in a dominant knowledge strategy for each segment. For example, Pisano (1994), in studying manufacturing process development projects in pharmaceuticals, concluded that firms in different environments had different approaches for learning. For the above reasons, we believe that within a given industry, groups of firms do exist with different knowledge strategies.

From the above argument, it also follows that performance will differ for firms following different knowledge strategies for the following three reasons. First, if the industry recipe is changing, the groups of firms that are able to adapt quicker, such that their current cognitive frames are closer to reality, will be more successful. Second, there may be superior knowledge strategies for an industry, but only firms with the prerequisite rare resources and capabilities will be able to pursue these strategies. Other firms would be forced to follow a knowledge strategy commensurate with their assets. Third, industry segments may differ in their profitability due to the industry structure.

It is our contention that there are similar knowledge strategies in many industries, particularly in industries with dynamic and complex (hypercompetitive) environments where organizational knowledge is clearly the firm's preeminent resource. For different knowledge strategies there are examples of firms in other 
industries that have been successful, and firms that have been unsuccessful. Industry characteristics such as the rate of change, the nature of the key technologies, the importance of economies of scale and scope, and the degree of competition will influence the appropriability of profits from an innovation. Also, for some firms the risk associated with failure may be very high suggesting a more conservative knowledge strategy may be appropriate. Thus, whereas the knowledge strategies exist in other industries, the characteristics of the industry will determine which strategies can be successful.

\section{Generic Knowledge Strategies}

Above, we outlined the following four elements of a knowledge strategy, each requiring a focus in a direction and involving tradeoffs:

(1) Internally vs. externally sourced knowledge.

(2) Enhanced vs. new knowledge.

(3) Fast vs. slow speed of learning.

(4) Depth vs. breadth of knowledge-base.

If we simplify each of the elements to two dimensions, there are 16 different combinations of the four strategic decisions. These combinations are displayed in the $4 \times 4$ matrix in Table 1 and are referred to as generic knowledge strategies. We realize that this simplification comes at a cost of not accounting for firms that (a) are balanced between the two dimensions (which is possible even though we discussed above how this may be difficult) and (b) are at an unhealthy extreme of one of the dimensions, such that the company is neglectful in other areas. We will discuss these circumstances later.

Our intent in developing these generic knowledge strategies is not to try to determine a single strategy that is superior in all situations. On the contrary, there is no one specific strategy that can assure a sustainable competitive advantage and each of the strategies may be effective at different times. However, for a specific situation, some strategies will be more effective than others and some strategies will be inappropriate. The specific conditions that will determine the effectiveness of each of the generic knowledge strategies are industry characteristics, organizational resources and capabilities, and the nature of the knowledge associated with the development of products in the industry. The following are several examples of generic knowledge strategies and a discussion when they are and are not effective. These four generic knowledge strategies are discussed in detail because (a) they are clearly distinct from each other, and (b) they best illustrate the theoretical issues discussed above.

Explorer (Strategy 2). Strategy 2 is an aggressive, focused strategy typically followed by technological leaders in a certain area. The focus is on the rapid development of new knowledge, mostly in a specific area. Since the focus is in a narrow field of study the firm will be able to primarily create the new knowledge internally. An advantage of internal learning in this situation is that it ensures a 
Table 1

Generic Knowledge Strategy Typology

\begin{tabular}{|c|l|l|l|l|c|}
\hline \multicolumn{2}{|c|}{} & \multicolumn{2}{l|}{ More Internal Focus } & \multicolumn{2}{l|}{ More External Focus } \\
\cline { 2 - 6 } & & $\begin{array}{l}\text { More Enhanced } \\
\text { Knowledge }\end{array}$ & $\begin{array}{l}\text { More New } \\
\text { Knowledge }\end{array}$ & $\begin{array}{l}\text { More Enhanced } \\
\text { Knowledge }\end{array}$ & $\begin{array}{l}\text { More New } \\
\text { Knowledge }\end{array}$ \\
\hline \multirow{2}{*}{ Narrow Breadth } & Faster Learning & Strategy 1 & Strategy 2 & Strategy 3 & Strategy 4 \\
\cline { 2 - 7 } & Slower Learning & Strategy 5 & Strategy 6 & Strategy 7 & Strategy 8 \\
\hline \multirow{2}{*}{ Broad Breadth } & Faster Learning & Strategy 9 & Strategy 10 & Strategy 11 & Strategy 12 \\
\cline { 2 - 7 } & Slower Learning & Strategy 13 & Strategy 14 & Strategy 15 & Strategy 16 \\
\hline
\end{tabular}


deeper understanding and the knowledge will be able to be integrated with other knowledge areas more efficiently than external learning. In this situation, focusing on speed and new knowledge enables firms to maximize their competitive advantage and first-in advantages. If the firm proceeded more cautiously and focused primarily on enhancing its knowledge-base in only a narrow area (a Strategy 1), the resultant competitive advantage would be minimal. Additionally, if a firm used this aggressive strategy focusing on a broad area (a Strategy 10), the firm may run the risk of not having a sense of direction and projects in critical knowledge areas may not get adequate funding due to limited resources and management attention. For example, AT\&T, which followed a Strategy 10 during the late 1980's and early 1990's, recently reorganized and shifted to a Strategy 2, citing these specific reasons. More likely, if a firm is to sustain a knowledge strategy of internally focusing on predominantly new knowledge in a broad area, it would need to slow down its learning process to maintain a sense of control and not become chaotic, which we identify as Strategy 14. In summary, the four elements of Strategy 2 appear to fit well together and are mutually reinforcing, creating a cohesive generic knowledge strategy.

Strategy 2 has some similarities to March's (1991) exploration type of organizational learning, thus, to maintain consistency with the established literature we refer to this generic knowledge strategy as the Explorer strategy. This strategy is most likely to be successful when (a) the firm has the established capabilities to generate and apply the new knowledge to a commercializable product, and (b) the firm is able prevent others from rapidly imitating its advances. It will probably be most successful in industries that are based more on tacit knowledge, have long lead times, and have an effective patent system. A disadvantage of this strategy is that it is costly. Thus, it would not be appropriate to use this strategy in conditions where competitors could quickly imitate any new products, eliminating profits and the ability to repay development costs. Examples of successful Explorers are Netscape, Ben and Jerry's, Abbott, Pfizer, and many biotechnology firms.

Exploiter (Strategy 5). Whereas Strategy 2 has similarities to March's (1991) concept of exploration, Strategy 5 has similarities to what he refers to as the exploitation type of organizational learning. This generic knowledge strategy, which we term Exploiter, enhances and maximizes the returns from its current knowledge-base more than trying to generate new knowledge. The Exploiter typically focuses on internal learning, a narrow breadth, and learns at a relatively slower rate. Strategy 13 is similar to the Exploiter strategy, except it focuses on a broader knowledge-base, which would require the vast resources of a larger company. Following the Exploiter strategy, the firm refines and becomes very efficient at its current practices. It maximizes its short-term profits by optimally using its current resources. However, this may be self-destructive in the long-term since there is no development of new knowledge, which is required for long-term success (March, 1991). The firm may become a leader and the most efficient in a knowledge area that no longer leads to a competitive advantage. 
This strategy is probably most successful in more mature industries where radical, new advances rarely occur. Thus, the firms can develop a competitive advantage by fine-tuning current knowledge areas, without competitors making their area of expertise obsolete. Conversely, the Exploiter strategy is probably not appropriate in rapidly changing industries where competitors are frequently coming up with new creative ideas. Examples of successful Exploiters are Honda, Toyota, Johnson \& Johnson and Compaq.

Imitator (Strategy 16). As the name implies, firms that follow this strategy are very good at imitating others, and they focus on new knowledge in a broad area. However, to excel at this type of external learning they would be required to have "absorptive capacity" in many diverse knowledge areas to be able to understand, interpret and implement these many new ideas (Cohen \& Levinthal, 1990). To successfully implement different radical changes simultaneously across a broad knowledge-base would be very difficult. The firm would need to follow a slower learning rate to allow the different, and especially complementary, knowledge areas to evolve together and to allow management to understand and manage the complexity of the situation. The competitive advantage of these firms would not necessarily be their ability to generate new knowledge, since their primary focus is on external learning, but would be their unique ability to integrate different, radically-changing knowledge areas, similar to what Kogut and Zander (1992) refer to as "combinative capability." Following this strategy firms would avoid the high costs associated with discovering new knowledge and typically would offer customers high quality products at a lower price. A vulnerability of this strategy is that it may be very difficult to develop a unique combinative capability that others can not imitate. It would probably be most successful in industries that are based more on explicit knowledge and where patents are difficult to enforce. It would be inappropriate in a scenario where patents are effective and it is difficult to imitate competitors because innovations are based on tacit knowledge and there is high causal ambiguity. Examples of firms following an Imitator strategy are Cooper Tire and Rubber and generic drug companies.

Passive Learner (Strategy 7). Passive Learners, who follow Strategy 7 , do not follow an aggressive approach to expanding the firm's knowledgebase. Following this strategy, firms focus on incremental improvements in a narrow knowledge area, externally source the new ideas, and proceed through the learning process relatively slowly. The obvious problem with this strategy is that there is no creation of a competitive advantage. Other competitors have access to the same improvements and implementation should be relatively easy for many competitors since the advancements are only incremental and in a focused area. In addition, the learning process is followed relatively slow, such that other firms will probably be able to implement the relatively simple improvements more rapidly.

Probably the only situation where this strategy can be implemented over a long period of time is in a very stable industry when the company already has 
some other type of competitive advantage established, such as strong brand name or superior location. An example of this strategy is Personal Products Company (a Johnson and Johnson Company) with its Stayfree feminine hygiene products. Stayfree was the market leader throughout the 1960's, 70's and 80's and had very high brand loyalty. They rarely made improvements to their product or processes, and the minor improvements they made were only implemented after their competitors established them as reliable. Little effort was spent attempting to generate new knowledge internally, as the product line was clearly viewed as a "cash cow." Their brand image was so strong that they were able to maintain market leadership for several decades. But eventually their competitor, Proctor and Gamble who followed a more aggressive knowledge strategy, developed a far superior product, the Always line, and became the new industry leader. Personal Products Company is now mostly unprofitable and is faced with the difficult challenge of radically changing its knowledge strategy and corporate culture, a fate encountered by most Passive Learners.

\section{Looking Beyond a Dichotomous Approach}

In the above discussion, we simplified each of the four elements of a knowledge strategy into two dimensions to generate generic knowledge strategies. Using such a configurational approach in studying the complexity associated with organizational phenomena can improve our understanding by identifying and analyzing distinct, internally consistent clusters of processes rather than by searching for consistent behavior among all organizations (Meyer, Tsui \& Hinings, 1993; Mintzberg, 1990). However, by only looking at this simplified version of knowledge strategies we may neglect some key issues. Specifically, the typology illustrated in Table 1 does not address (a) extreme cases of one of the strategy elements, and (b) the combination of more than one generic knowledge strategy (in a similar manner that Porter's strategies of low cost and differentiation may be combined in certain circumstances).

Each of the four elements of a firm's knowledge strategy involve tradeoffs. Any of these areas could be pushed to an unhealthy extreme if other areas are neglected. For example, the Explorer strategy (Strategy 2) could overemphasize internal learning at the neglect of external learning. Bierly and Chakrabarti (1996a), using patent analyses, identified that several firms in the pharmaceutical industry are essentially isolated from the rest of the research being done in the industry. Even though these companies spend as much or more in R\&D, their knowledgebases generally are not as deep as their competitors who also incorporate advancements from outside sources. The Explorers tend to be more like Loners and are not as successful as others. Cray Computer Systems, Carter Wallace, and Kodak are examples of firms that follow such a Loner strategy. At the other extreme, firms focusing exclusively on external learning, and do not internally learn enough to achieve absorptive capacity are likely to fail (Cohen \& Levinthal, 1990). In a similar manner, an extreme position in any of the other three elements of a knowl- 
edge strategy (i.e. too fast or slow, too narrow or broad, too much focus on new or enhanced knowledge) is also problematic.

A second key issue is whether or not these generic knowledge strategies can be combined. Earlier we provided reasons why most companies tend to focus more on specific dimensions and have difficulty excelling at both directions of the elements of knowledge strategy simultaneously: lack of resources, cultural conflict, and a need for internal consistency. However, detailed case analyses of a few exceptional firms seems to indicate that it is possible to combine generic knowledge strategies. For example, Leonard-Barton (1995) illustrated how Chaparral Steel has been able to not only balance the tradeoffs between internal and external learning, but excel in both areas. Merck could likewise be viewed as a firm that is outstanding at both internal and external learning. In a similar manner, March (1991) illustrated that most firms focus primarily on either exploration or exploitation, but there are a few exceptional firms that can do both. Thus, our knowledge strategy typology may provide a general guideline for strategic action that ensures consistency, but in some cases a combination of strategies may be the appropriate benchmark for firms to strive to meet. But, as stated earlier, the problem with combination strategies is that the strategic direction of firms may become less clear.

\section{Implications}

We believe the development of a generic knowledge strategy typology has major implications in two different, but related ways. First, such a typology has practical implications for managers in that it provides a guideline to assist in the formulation and implementation of a consistent, effective strategy. Second, the typology provides organizational researchers who are concerned with theory development a tool to classify firms that allows for the better understanding of complex issues that are unique to specific types of firms.

\section{Managerial Implications}

The use of the above typology offers managers a new knowledge-based perspective of strategic issues. The typology can provide a guide for knowledgebased strategic decisions that will ensure internal consistency and the development of core competencies that will lead to sustainable competitive advantages. Most managers are unfamiliar with the concept of knowledge management and have not directed their attention toward these strategic choices. Figure 1 provides a simple circular framework to use for the identification and continuous development of a firm's knowledge strategy. The steps in this process, which are not necessarily sequential, are as follows.

\section{Identification of current knowledge-base and past generic knowledge strat-} egy. It is imperative that a firm has an accurate picture of its own resources. An audit of its own knowledge-base would identify current core competencies and 
Figure 1

Continuous Development of a Knowledge Strategy

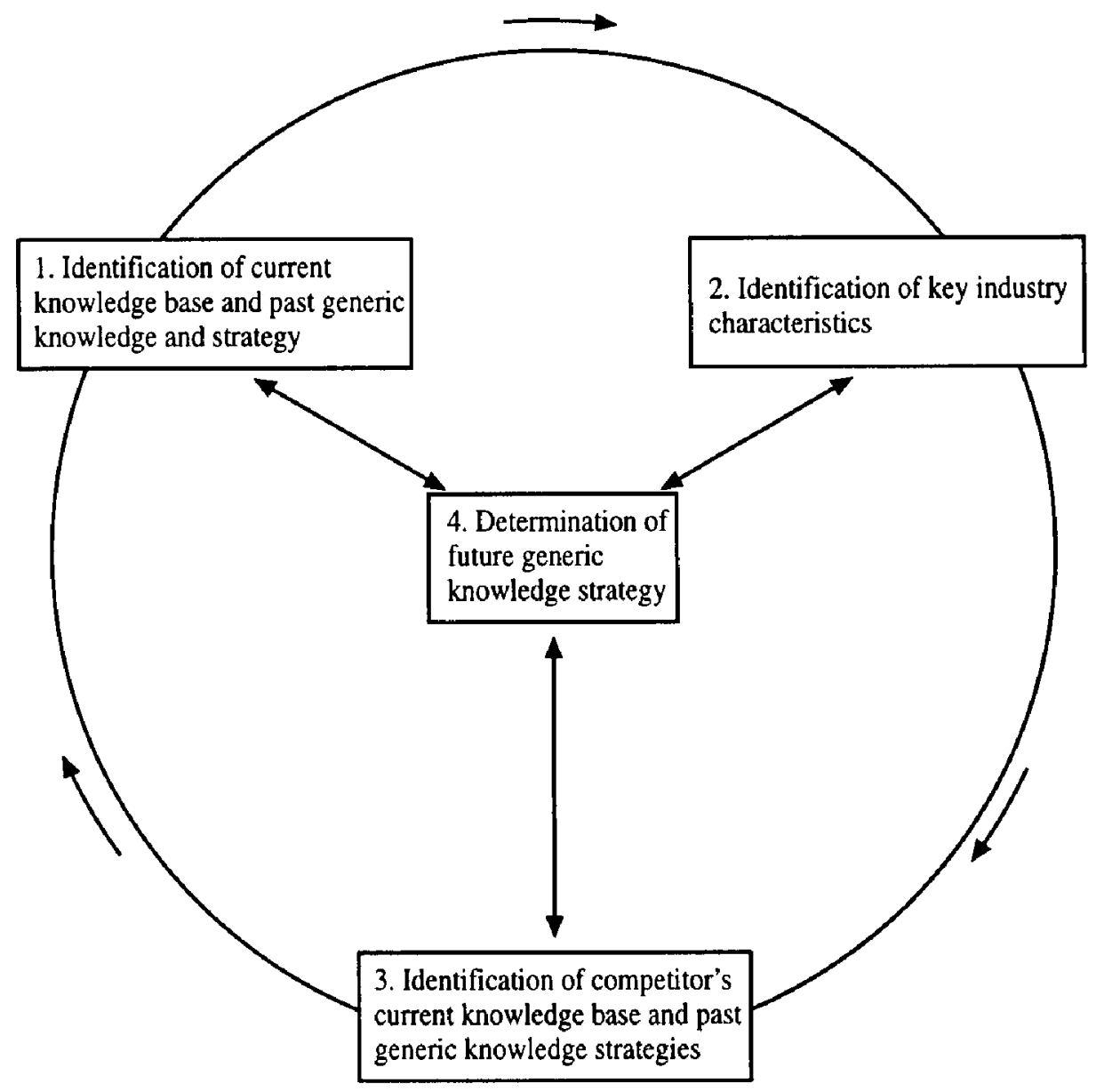

areas of weakness. It is also vital that a firm identifies how its current knowledgebase evolved or, in other words, what was its past knowledge strategy. The knowledge-base is path dependent to a degree and can be viewed as having momentum in a certain direction. Without intervention by management, the future knowledge strategy will most likely be the same as the past knowledge strategy, since these methods of learning become institutionalized in the organization's culture. This may or may not be problematic, based on the other factors discussed below, but either way it is important for managers to know the direction they are currently heading.

2. Identification of key industry characteristics. In the above sections, we discussed under what conditions certain generic knowledge strategies are and are 
not appropriate. Specifically, the dynamism of the industry, the tacitness of the knowledge associated with the products in the industry, the ability of competitors to imitate each other, the level of industry rivalry, and the relatedness of complementary knowledge areas are all factors that influence the success of different knowledge strategies. Managers must identify these key industry characteristics and have an understanding how they are changing before determining their future knowledge strategies.

3. Identification of competitors' current knowledge-base and past generic knowledge strategies. Strategy and tactics can not be developed and implemented without appreciating the dynamic interactions among firms. An apparently ideal strategy for a given set of industry characteristics may be unsuccessful because (a) other powerful players are also pursuing that strategy, creating abnormally high rivalry among the group, and (b) competitors' retaliatory responses may change industry characteristics and the nature of competition. In other words, a firm's knowledge strategy should be dependent upon the actual and anticipated strategic decisions of competitors. Thus, before a firm develops and implements its own knowledge strategy, it should identify its competitors' current knowledge-base, and their past and future knowledge strategies.

4. Determination of future generic knowledge strategy. Based on its current knowledge-based resources, key industry characteristics, and competitors' knowledge strategies, a firm can formulate its own knowledge strategy for the future. The nature of the competitive environment will determine what set of generic knowledge strategies are most appropriate for the specific industry. From these, the firm should choose a specific generic knowledge strategy that best utilizes its unique knowledge-base that has developed over time. The knowledge strategy will provide consistency throughout the organization concerning how and in what direction the organization learns and changes its knowledge-base. As Figure 1 attempts to illustrate, this process is not a sequential, static process, but rather a dynamic, continuous process. Each of the components in Figure 1 are continually changing and are interactive with the other components. The components are placed in a wheel configuration to illustrate the circularity of the process and as a means of emphasizing that the process "rolls on" over time.

\section{Research Implications}

Typologies and taxonomies assist researchers in understanding complex phenomena by promoting the study of similar types of firms. In the strategic management field, the following configurational approaches have greatly improved our understanding of the nature of competition within an industry: generic strategy typologies (e.g. Miles \& Snow, 1978; Porter, 1980), strategic archetypes (e.g. Miller \& Friesen, 1978), and strategic groups (Caves \& Porter, 1977; McGee \& Thomas, 1986). Each of these classifications have helped researchers better understand complex phenomena and these advances may not have occurred if only the entire industry was analyzed as a whole. 
In a similar manner, the generic knowledge strategy typology developed in this paper provides a means of classifying different types of firms to better understand their behavior and determinants of success. Of course, the main difference between our typology and the classifications listed above is that ours is grouping firms based on knowledge and learning characteristics, while the others used different variables. Clearly, the next step is to conduct empirical research to test the propositions developed throughout this paper. Specifically, empirical research questions that follow from this paper are: Do all of the generic knowledge strategies exist and which ones are most prevalent? Are certain generic knowledge strategies more highly correlated with profitability in different industry settings? How frequently do firms change their generic knowledge strategies? Are firms that are more flexible and change their knowledge strategies in response to a change in the environment more successful than firms that maintain a stable knowledge strategy? Additionally, detailed case studies could be used to better understand how knowledge strategies evolve over time and identify barriers and facilitators to the implementation of different knowledge strategies.

\section{References}

Argyris, C. (1982). Reasoning, learning. and action: Individual and organizational. San Francisco: Jossey-Bass.

Argyris, C., \& Schon, D. (1978). Organizational learning: A theory of action perspective. Reading, MA: Addison-Wesley Publishing.

Barney, J. (1991). Firm resources and sustained competitive advantage. Journal of Management. 17 (1), 99-119.

Bierly, P., \& Chakrabarti, A. (1996a). Generic knowledge strategies in the U.S. pharmaceutical industry. Strategic Management Journal. 17 (Winter Special Issue), 123135.

Bierly, P., \& Chakrabarti, A. (1996b). Determinants of technology cycle time in the U.S. pharmaceutical industry. R\&D Management. 26, 115-126.

Bierly, P., \& Chakrabarti, A. (1996c). Technological learning, strategic flexibility, and new product development in the pharmaceutical industry. IEEE Transactions on Engineering Management. $43,368-380$.

Bierly, P., \& Hămäläinen, T. (1995). Organizational learning and strategy. Scandinavian Journal of Management. 11, 209-224.

Bierly, P., \& Spender, J. C. (1995). Culture and high reliability organizations: The case of the nuclear submarine. Journal of Management, 21, 639-656. 
Bower, J. L., \& Hout, T. M. (1988). Fast-cycle capability for competitive power. Harvard Business Review, 66 (6), 110-118.

Brown, J. S., \& Duguid, P. (1991). Organizational learning and communities-of-practice: Toward a unified view of working, learning, and innovation. Qrganization Science. $\underline{2}, 40-57$.

Caves, R. E., \& Porter, M. E. (1977). From entry barriers to mobility barriers: Conjectural decisions and contrived deterrence to new competition. Quarterly Journal of Economics. 91, 241-262.

Chakrabarti, A. K. (1974). Role of product champion in innovation. California Management Review. 17 (2), 58-62.

Chesbrough, H. W., \& Teece, D. J. (1996). When is virtual virtuous? Organizing for innovation. Harvard Business Review, January-February, 65-73.

Cohen, W. M., \& Levinthal, D. A. (1990). Absorptive capacity: A new perspective on learning and innovation. Administrative Science Quarterly. 35, 128-152.

Conner, K. R., \& Prahalad, C. K. (1996). A resource-based theory of the firm: Knowledge versus opportunism. Organization Science. 7, 477-501.

Cyert, R. M., \& March, J. G. (1963). A behavioral theory of the firm. Englewood Cliffs, NJ: Prentice-Hall.

Daft, R. L., \& Weick, K. E. (1984). Toward a model of organizations as interpretation systems. Academy of Management Review, 9, 284-295.

Fiol, C. M., \& Lyles, M. A. (1985). Organizational learning. Academy of Management Review, 10, 803-813.

Garvin, D. A. (1993). Building a learning organization. Harvard Business Review, JulyAugust, 78-91.

Gilad, B., \& Gilad, T. (1988). The business intelligence system. New York: American Management Association.

Gioia, D. A., \& Poole, P. P. (1984). Scripts in organizational behavior. Academy of Management Review, 9, 449-459.

Gold, B. (1987). Approaches to accelerating product and process development. Journal of Product Innovation Management, 4, 81-88.

Grant, R. M. (1996a). Toward a knowledge-based theory of the firm. Strategic Management Journal, 17 (Winter Special Issue), 109-121. 
Grant, R. M. (1996b). Prospering in dynamically-competitive environments: Organizational capability as knowledge integration. Organization Science. 7, 375-387.

Grant, R. M. (1991). The resource-based theory of competitive advantage. California Management Review, 33 (3), 114-135.

Hamel, G. (1991). Competition for competence and inter-partner learning within international strategic alliances. Strategic Management Journal. 12 (Summer Special Issue), 83-103.

Hamel, G., Doz, Y., \& Prahalad, C. K. (1989). Collaborate with your competitors-and win. Harvard Business Review, 67 (1), 133-139.

Hamel, G., \& Prahalad, C. K. (1994). Competing for the future. Boston: Harvard Business School Press.

Hedberg, B., Nystrom, P. C., \& Starbuck, W. H. (1976). Camping on seesaws: Prescriptions for a self-designing organization. Administration Science Ouarterly.2, 39-52.

Hedlund, G. (1994). A model of knowledge management and $\mathrm{N}$-form corporation. Strategic Management Journal, 15 (Summer Special Issue), 73-90.

Henderson, R., \& Clark, K. (1990). Architectural innovation: The reconfiguration of existing product technologies and the failure of established firms. Administrative Science Quarterly. 35, 9-30.

Henderson, R., \& Cockburn, I. (1994). Measuring competence? Exploring firm effects in pharmaceutical research. Strategic Management Journal. 15 (Winter Special Issue), 63-84.

Herriot, S. R., Levinthal, D., \& March, J. G. (1985). Learning from experience in organizations. American Economic Review, 75, 298-302.

Hitt, M. A., Hoskisson, R. E., Ireland, R. D., \& Harrison, J. S. (1991). Effects of acquisitions on R\&D inputs and outputs. Academy of Management Joumal, 34, 693-706.

Huber, G. P. (1991). Organizational learning: The contributing processes and the literatures. Organization Science, 2, 88-115.

Huber, G. P. (1982). Organizational information systems: Determinants of their performance and behavior. Management Science, 28, 135-155.

Huber, G. P., \& Daft, R. L. (1987). The information environments of organizations. In F. Jablin, L. Putman, K. Roberts and L. Porter (Eds.), Handbook of organization communication. Beverly Hills, CA: Sage. 
Imai, K., Nonaka, I., \& Takeuchi, H. (1988). Managing the new product development process: How Japanese companies learn and unlearn. In M. Tushman and W. Moore (Eds.), Readings of the management of innovation. Cambridge, MA: Ballinger.

Kanter, R. M. (1988), When a thousand flowers bloom: Structural, collective, and social conditions for innovation in organization. In L. L. Cummings and B. M. Staw (Eds.), Research in Qrganizational Behavior: Vol, 10, 169-211.

Kessler, E. H., \& Chakrabarti, A. K. (1996). Innovation speed: A conceptual model of context, antecedents, and outcomes. Academy of Management Review, 21, 11431191.

Kogut, B., \& Zander, U. (1992). Knowledge of the firm, combinative capabilities, and the replication of technology. Organization Science. 3, 383-397.

Lant, T. K., \& Mezias, S.J. (1992). An organizational learning model of convergence and reorientation. Organization Science, $3,47-71$.

Lei, D., Hitt, M. A., \& Bettis, R. (1996). Dynamic core competencies through meta-learning and strategic context. Journal of Management. 22, 549-569.

Leonard-Barton, D. (1995). Wellsprings of knowledge. Boston: Harvard Business School Press.

Leonard-Barton, D. (1992). Core capabilities and core rigidities: A paradox in managing new product development. Strategic Management Journal. 13, 111-125.

Levinthal, D., \& March, J. G. (1981). A model of adaptive organizational search. Journal of Economic Behavior and Organization, 2, 307-333.

Levinthal, D., \& March, J. G. (1993). The myopia of learning. Strategic Management Journal. 14 (Winter Special Issue), 95-112.

Levinthal, D., \& Myatt, J. (1994). Co-evolution of capabilities and industry: The evolution of mutual fund processing. Strategic Management Journal, 15 (Winter Special Issue), 45-62.

Lieberman, M. B., \& Montgomery, D. B. (1988). First-mover advantages. Strategic Management Journal. 9, 41-58.

Lippman, S. A., \& Rumelt, R. P. (1982). Uncertain imitability: An analysis of interfirm differences in efficiency under competition. Bell Journal of Economics, 13, 418-438.

Lounamaa, P. H., \& March, J. G. (1987). Adaptive coordination of a learning team. Management Science, 33, 107-123. 
Maidique, M. A., \& Patch, P. (1983). Corporate strategy and technological policy. In M. L. Tushman and W. L. Moore (Eds.), Readings in the management of innovation, Boston: Pitman, 273-285.

March, J. G. (1991). Exploration and exploitation in organizational learning. Qrganization Science, $2,71-87$.

McGee, J., \& Thomas, H. (1986). Strategic groups: Theory, research and taxonomy. Strategic Management Journal, 7, 141-160.

Meyer, A. D., Tsui, A. S., \& Hinings, C. R. (1993). Configurational approaches to organizational analysis. Academy of Management Journal. 36, 1175-1195.

Meyer, C. (1993). Fast cycle time: How to align purpose, strategy, and structure for speed. New York: Free Press.

Miles, R. E., \& Snow, C. C. (1978). Qrganizational strategy, structure and process. New York: McGraw-Hill.

Miller, D. (1996). A preliminary typology of organizational learning: Synthesizing the literature. Journal of Management. 22, 485-505.

Miller, D., \& Friesen, P. (1978). Archetypes of strategy formulation. Management Science. 24, 921-933.

Mintzberg, H. (1990). Strategy formation: Schools of thought. In J. F. Fredrickson (Ed.), Perspectives on strategic management. Philadelphia: Harper Business.

Mowery, D. C., Oxley, J. E., \& Silverman, B. S. (1996). Strategic alliances and interfirm knowledge transfer. Strategic Management Journal, 17 (Winter Special Issue), 77 92.

Nelson, R., \& Winter, S. (1982). An evolutionary theory of economic change. Cambridge, MA: Harvard University Press.

Nonaka, I. (1991). The knowledge-creating company. Harvard Business Review, November-December, 96-104.

Nonaka, I. (1994). A dynamic theory of organizational knowledge creation. Organization Science, 5, 14-37.

Nystrom, P. C., \& Starbuck, W. (1984). To avoid organizational crises, unlearn. Organizational Dynamics. 13, 53-65.

Peteraf, M. A. (1993). The cornerstones of competitive advantage: A resource-based view. Strategic Management Journal, 14, 179-191. 
Pisano, G. P. (1994). Knowledge, integration, and the locus of learning: An empirical analysis of process development. Strategic Management Journal. 15 (Winter Special Issue), 85-100.

Polanyi, M. (1966). The tacit dimension. London: Routledge \& Kegan Paul.

Porter, M. (1980). Competitive strategy. New York: Free Press.

Prahalad, C. K., \& Hamel, G. (1990). The core competence of the corporation. Harvard Business Review, 68 (3), 79-91.

Reed, R., \& DeFillipi, R. J. (1990). Casual ambiguity, barriers to imitation, and sustainable competitive advantage. Academy of Management Review, 15, 88-102.

Sanchez, R., \& Mahoney, J. T. (1996). Modularity, flexibility, and knowledge management in product and organization design. Strategic Management Journal. 17 (Winter Special Issue), 63-76.

Senge, P. M. (1990). The fifth discipline. New York: Doubleday.

Simon, H.A. (1991). Bounded rationality and organizational learning. Organization Science. $2,125-134$.

Spender, J.-C. (1989). Industry recipes: The nature and sources of managerial judgement. Oxford: Basil Blackwell.

Spender, J.-C. (1994), Organizational knowledge, collective practice and penrose rents. International Business Review. 3, 353-367.

Spender, J.-C. (1996). Making knowledge the basis of a dynamic theory of the firm. Strategic Management Journal. 17 (Winter Special Issue), 45-62.

Stalk, G. (1988). Time - the next source of competitive advantage. Harvard Business Review, 66 (5), 41-51.

Stalk, G., Evans, P., \& Shulman, L. (1992). Competing on capabilities: The new rules of corporate strategy. Harvard Business Review, March-April, 57-69.

Teece, D. J., Pisano, G., \& Shuen, G. (1997). Dynamic capabilities and strategic management. Strategic Management Journal. 18, 509-533.

Tushman, M., \& Anderson, P. (1986). Technological discontinuities and organizational environments. Administrative Science Quarterly, 31, 439-465.

Volberda, H. W. (1996). Toward the flexible form: How to remain vital in hypercompetitive environments. Organization Science. . 3, 359-374. 
Webster's third new international dictionary (1981). Springfield, MA: Merriam-Webster.

Weick, K. E. (1991). The nontraditional quality of organizational learning. Organization Science. 2, 116-124.

Wheelwright, S. C., \& Clark, K. B. (1992). Revolutionizing product development. New York: Free Press.

Winter, S. (1987). Skill and knowledge as strategic assets. In D. Teece (Ed.), The competitive challenge, 159-184. Cambridge, MA: Ballinger.

Zander, U., \& Kogut, B. (1995). Knowledge and the speed of the transfer and imitation of organizational capabilities: An empirical test. Organization Science. 6, 76-92.

\section{Endnotes}

${ }^{1}$ Similar to Conner and Prahalad (1996), we view the knowledge-based view of the firm as a similar approach to, but narrower than the resource-based view of the firm. The resource-based view explains performance differences by identifying unique, valuable and inimitable resources and capabilities; but, in most cases, the resource that ultimately leads to a sustainable competitive advantage is the firm's unique knowledge-base (Grant, 1991; Barney, 1991; Peteraf, 1993).

${ }^{2}$ Levinthal and Myatt (1994) discussed the co-evolution of firms' organizational capabilities within an industry. It is an interesting proposition that within a very stable environment with a dominant industry recipe, the knowledge strategies of all firms may converge. However, we believe this situation to be a very limited case.

Paul E. Bierly III (Ph.D., Rutgers University) is an Assistant Professor at James Madison University. Earlier, he was a submarine officer in the U.S. Navy's Nuclear Power Program and he worked in manufacturing for Johnson and Johnson, Inc. His current research is in the areas of the management of technology, knowledge management and strategic alliances. His research has been recently published in Strategic Management Journal, Journal of Management, IEEE Transactions on Engineering Management, R\&D Management, and several other management journais. 